\title{
Microfinanças e Política Pública na América Latina
}

\author{
Maria Cristina Cacciamali \\ José Paulo Zeetano Chahad \\ Fábio Tatei*
}

Resumo: Este trabalho visa analisar o papel dos programas de microcrédito em diferentes países, focalizando sua natureza, seu desempenho e, quando possível, o impacto sobre o nível de renda das famílias, ou sobre a performance dos pequenos e microempreendimentos. Em especial destacamos a importância da microfinança no espectro das políticas públicas que são desenvolvidas na América Latina com o objetivo de ampliar o bem-estar dos estratos mais pobres e de se aproximar das Metas do Milênio da Organização das Nações Unidas (ONU).

Palavras-chaves: Microcrédito, Microfinança, Avaliação de Programas de Microfinanças, Políticas Públicas na América Latina.

Abstract: This paper aims to analyze the role of microcredit programs in different countries, focusing on their nature, performance and impact on the families' income or on the developing of small and microenterprises. In particular, the study highlights the importance of microfinance in the spectrum of public policies that are implemented in Latin America, with the objective of improving the well-being of the poor and reaching the UN Millennium Goals.

Keywords: Microcredit, Microfinance, Microfinance's Programs Evaluation, Public Policies in Latin America.

\footnotetext{
* Maria Cristina Cacciamali: Professora Titular da Faculdade de Economia, Administração e Contabilidade (FEA), do Programa de Pós-Graduação Interunidades em Integração da América Latina da Universidade de São Paulo (PROLAM/ USP) e pesquisadora sênior do CNPq. E-mail: cciamali@uol.com.br. José Paulo Chahad: Professor Titular da FEA/USP e Pesquisador sênior da FIPE. E-mail: jpchahad@usp.br. Fábio Tatei: Bacharel em Economia pela FEA/USP e pesquisador da FIPE. E-mail: ftatei@gmail.com. Os autores são membros do Núcleo de Estudo e Pesquisa de Política Internacional. Estudos internacionais e políticas comparadas (NESPI) - CNPq/FEA/PROLAM/USP. Recebido em 02/06/08 e aceito em 13/06/08.
} 


\section{Introdução}

O objetivo do presente artigo é o de analisar programas de microcrédito, uma das atividades principais das instituiçóes de microfinanças, de diferentes países, focalizando, especialmente, a sua natureza, seu desempenho e, quando possível, o seu impacto sobre o nível de renda das pessoas ou sobre o desempenho dos pequenos estabelecimentos. Destaca-se, ainda, a importância da microfinança no espectro das políticas públicas que são desenvolvidas na América Latina com o objetivo de ampliar o nível da vida material dos estratos mais pobres e de permitir atingir as metas do Milênio propostas pela Assembléia da ONU no ano de 2000 . $^{1}$

Inicialmente, cabe destacar que o campo da microfinança define-se crescentemente em três espaços: na ciência interdisciplinar sobre a qual criou e desvenda uma base consolidada de conhecimento; na prática das políticas públicas em nível global, visto a sua característica de seguir princípios de mercado; e na extensão e aprofundamento dos mercados, estendendo as atividades financeiras para populaçóes e regiōes onde bancos e outras instituições financeiras de maior porte não atuam.

Com relação ao primeiro aspecto, devemos ressaltar que a análise das microfinanças se constitui em objeto de pesquisa complexo, pois visa analisar a natureza, estratégia, capilaridade do crédito e outros serviços financeiros, como seguros e poupanças, entre outros, às camadas sociais populares e o impacto que esses serviços produzem na vida material dos usuários. A integração de áreas de conhecimento técnico como finanças, contabilidade, matemática e estatística com as ciências humanas e sociais aplicadas, como a economia, a psicologia e a sociologia, implica numa produção científica que supera a contribuição singular de cada uma dessas áreas.

O segundo aspecto, por outro lado, nos remete à expansão e magnitude desse segmento. O campo da microfinança se amplia desde $1980 \mathrm{em}$ todas as regióes do globo. Com relação à América Latina, estudo de Christen estima que, entre 1998 e 2003, o número de Organizaçôes Não-Governamentais

\footnotetext{
${ }^{1}$ Os programas de microfinanças devem estender os serviços financeiros aos estratos pobres da população, por exemplo, acesso ao crédito, oferta de diversos tipos de seguro, poupança, remessa de divisas, entre outros. No que se refere às metas do Milênio entende-se que os programas devem ampliar o acesso aos serviços de educação e saúde, acesso à água e outros serviços sociais.
} 
(ONGs), que operava com microfinanças, aumentou de $210 \%$ e o número de Bancos Comerciais que passaram a oferecer esses serviços cresceu de 363\% (CHRISTEN, 2005). Um quadro mais estável é apresentado pelo Sistema Mix-Market, adotado pelo Banco Mundial. ${ }^{2}$ Em 2006, segundo a fonte de dados mencionada, encontram-se cadastradas pouco mais de 1.200 Instituiçóes de Microfinanças (Imfs), atendendo cerca de 58 milhóes de famílias pobres. Mais de 2/3 das famílias atendidas situam-se nos países asiáticos, 35,7\% se encontram no Sudeste da Ásia, e as demais no Leste da Ásia/Pacífico. Em relação às demais regiōes do globo, a distribuição dos credores segue a seguinte ordem de importância: 16\% na América Latina e Caribe, $11 \%$ na África e Oriente Médio e 3\% América do Norte. ${ }^{3}$

$\mathrm{O}$ terceiro aspecto se baseia na tríplice justificativa sobre a necessidade da expansão das microfinanças e a sua absorção, quando houver escala, pelos bancos comerciais. A primeira justificativa refere-se ao fato de que as microempresas representam um segmento chave para a manutenção do emprego, especialmente dos trabalhadores menos qualificados. $\mathrm{O}$ segundo argumento diz respeito à utilização do microcrédito como um instrumento para mitigar a situação de pobreza e o terceiro ponto enfatiza o acesso ao crédito como motor do desenvolvimento econômico.

Com base nos pontos apresentados, este trabalho foi estruturado em duas seções. Na primeira seção tratamos dos aspectos teóricos que justificam as açóes no campo das microfinanças incentivadas pelo estado ou pelo setor privado devido às assimetrias do mercado de crédito que restringe o acesso ao crédito dos indivíduos mais pobres. Na segunda seção discutimos tipos e alcance dos métodos de avaliação e apresentamos resultados originários de estudos de avaliação implementados em 24 países economicamente

\footnotetext{
${ }^{2} \mathrm{Na}$ literatura não há consenso sobre os critérios que devem ser utilizados para mensurar o número de Imfs, que variam entre 1200 e 7000! Segundo a Organização Internacional do Trabalho (OIT), por exemplo, as estimativas, em 2005, giravam em torno de $3.000 \mathrm{Imfs}$, atendendo a 113 milhões de famílias pobres, angariando US\$ 40 bilhões em depósitos e distribuindo US\$ 50 bilhões, sempre em pequeno montante. Optamos pela estimativa do Banco Mundial/Mix Market pelo fato de: considerar Imfs consolidadas que mantém registro sistemático de suas operações; possibilitam estimar anualmente indicadores de desempenho, transparência, rentabilidade, qualidade da carteira de cliente e sustentabilidade, e mantêm um critério de classificação sobre a consistência e evolução dos indicadores. Deixamos claro, entretanto, que as informações do Mix-Market representam apenas a ponta do iceberg do sistema de microcrédito - público, para-público, privadas, sociedades filantrópicas etc.

${ }^{3}$ Conforme informações de CGAP (2007).
} 
retardatários, destacando-se países latino-americanos selecionados. Por fim, tecemos as nossas consideraçôes finais.

\section{Aspectos teóricos da microfinança}

A literatura especializada apresenta ampla variedade de estudos que abordam o desempenho de programas de microfinanças, em especial daqueles que tratam do microcrédito direcionado para famílias pobres, abarcando aspectos socioeconômicos como renda familiar, pobreza, atendimento médico, nutrição das crianças, escolaridade, freqüência escolar, desemprego, entre outros. ${ }^{4}$ Complementarmente, destaca-se o papel da geração de emprego como uma alternativa, direta ou indireta, para a redução da pobreza e desigualdade de renda. ${ }^{5}$

$\mathrm{O}$ mercado financeiro privado não estende os seus serviços à população mais pobre devido a um conjunto de assimetrias que se originam da própria função da atividade: realocar renda intertemporalmente. As assimetrias estão associadas, principalmente, à lacuna de informaçóes que o banco dispóe antes e depois da concessão do crédito.

Em primeiro lugar, o banco não dispóe de informaçóes suficientes sobre a viabilidade econômica do projeto que lhe é apresentado pelo tomador do empréstimo. Por esse motivo, o banco não consegue selecionar as propostas que lhe são apresentadas de acordo com critérios de menor risco, atendendo apenas as propostas que, explicita e objetivamente, lhe conferem menor risco. Esse comportamento de seleção adversa leva a duas situações: racionamento de crédito e aumento nos custos de transação. A primeira surge porque muitas propostas não são atendidas devido à falta de informaçóes adequadas; a segundo situação ocorre pela implantação de sistemas de informaçóes e de tomada de decisóes que permitam selecionar tomadores que, em tese, apresentem menor probabilidade de inadimplência. Os dois comportamentos elevam as taxas efetivas de juros.

Em segundo lugar, o banco se defronta com problemas de risco moral (moral hazard) depois da concessão do crédito. Isto porque não possui a capacidade de monitorar o desenvolvimento dos diferentes projetos que

\footnotetext{
${ }^{4}$ Para uma ampla abordagem desses estudos, ver Consultive Group to Assist the Poor e World Bank (2004) e Goldberg (2005). ${ }^{5}$ A discussão do tema para o caso brasileiro pode ser visto em Araújo e Lima (2006).
} 
receberam crédito, nem pode ter certeza quanto à disposição e capacidade dos devedores de honrar a dívida contraída. Assim, pode ser alvo de um comportamento oportunista, de risco moral. Essa atitude terá maior probabilidade de ocorrer se o custo de se tornar inadimplente para o tomador do empréstimo for menor do que aquele de arcar com a dívida ou, ainda, se o tomador puder obter alguma vantagem em um processo de renegociaçáo da dívida.

Os bancos procuram preservar-se do risco moral de duas formas. A primeira é por meio do desenvolvimento de sistemas de avaliação de risco para processos de seleção de tomadores e para o monitoramento das operaçóes de empréstimos. A segunda forma se dá através da elaboração de contratos que prevêem os casos de inadimplência. Entretanto, a garantia de pagamento dos empréstimos é usualmente assumida sob a forma de bens que constituam fontes de riqueza do tomador, por exemplo, imóveis. Esse instrumento evita custos maiores de monitoramento e, em caso de inadimplência, o banco poderá reaver o seu ativo principal.

Conforme pode ser observado nos parágrafos anteriores, os instrumentos, que os bancos adotam para a sua proteção excluem do mercado de crédito um conjunto de investidores que, embora possam apresentar empreendimentos economicamente viáveis, não possuem garantias reais. Esse comportamento atinge, em particular, investidores de pequeno porte e/ou do setor informal que, em geral, na possuem garantias reais para oferecer.

A existência de uma grande parcela de pequenos investidores que não é atendida pelo mercado de crédito provoca então uma fragmentação do sistema de crédito, donde paralelamente ao seu segmento formal, que provê crédito exclusivamente aos tomadores em condiçóes de se submeterem às suas exigências, opera outro não institucionalizado, caracterizado, principalmente, pela alta dispersão de taxas de juros e por sua atuação à margem da licitude, por exemplo, agiotas e credores familiares.

Dessa maneira, os serviços de microcrédito e outros serviços financeiros que mostram problemas similares, como os diversos tipos de seguros, por exemplo, surgem para atender as microempresas e as atividades do setor informal. O sistema de microfinanças é concebido apresentando alternativas para a seleção de clientes, avaliação de riscos e exigência de garantias, trazendo, 
em parte, soluçóes, para os problemas de seleção adversa e de risco moral.

\section{Tipos de ações de microcrédito e os seus resultados}

A escolha de programas bem sucedidos - boas práticas - no campo do microcrédito requerem, inicialmente, a definição de dois aspectos: a demarcação da unidade de pesquisa/análise e a valorização das diferentes metodologias de avaliação. ${ }^{6}$ No primeiro caso devemos destacar que, em geral, as avaliaçóes de impacto sobre o nível de renda e o emprego dos mais pobres, privilegiam dois objetos de pesquisa domicílios e pequenos empreendimentos, embora, nesse último caso, haja dificuldade de definição e identificação dessas empresas, bem como da extrapolação dos resultados para além do próprio empreendimento.

No que tange à valorização que devemos atribuir às diferentes metodologias de avaliação para selecionar resultados que definam as boas práticas, entendemos que as avaliaçóes de impacto - experimentais e quase experimentais - originam resultados mais robustos, seguidos dos estudos ou avaliaçóes de desempenho. Isto porque as primeiras possibilitam aferir se as alteraçóes observadas nas características avaliadas das unidades de pesquisa se devem diretamente a ação do crédito ou a fatores exógenos ao programa. Nesses termos, classificamos estudos de acordo com os critérios acima: avaliaçóes de impacto (Tipo I) e análises de desempenho (Tipo II) que passaremos a apresentar.

\section{Avaliação de impacto (Tipo I)}

Conforme apresentado anteriormente, as pesquisas de avaliações de impacto visam captar os efeitos diretos do microcrédito sobre as variáveis em análise a partir de instrumentos econométricos que confrontam dados de um grupo de tratamento -tomadores de empréstimo - em relação a um grupo de comparação ou grupo de controle - que não tomaram empréstimo. Uma das principais dificuldades de se formular uma avaliação de impacto apropriada deve-se ao viés de seleção da amostra, isto é, a formação inadequada de um

\footnotetext{
${ }^{6}$ A escolha da unidade de avaliação - indivíduo, domicílio, empreendimento etc. - é uma etapa importante de um processo de avaliação, cada um dessas unidades de pesquisa apresenta suas vantagens e desvantagens perante as demais. Veja-se, por exemplo, Hulme (2000, p. 79-98).
} 
grupo de controle que poderia acarretar distorçóes dos resultados estimados e, conseqüentemente, induzir a conclusóes errôneas. Portanto, tornam-se vitais os esforços na formação de um grupo de controle que se aproxime, o máximo possível do ideal, dado os custos e os prazos compatíveis com o projeto de avaliação.

Um exemplo de distorção que pode ser originada pelo viés de seleção é dado, no caso do Brasil, por Barros e Carvalho (2002) ao analisar o estudo de Passos e Costanzi (2002). Os últimos autores cruzaram dois bancos de dados do Ministério do Trabalho e Emprego do Brasil para avaliar o impacto do Programa de Geração de Emprego e Renda desse mesmo Ministério - Sistema de Acompanhamento do Proger (SAEP) e Cadastro Geral de Emprego e Desemprego (CAGED). O indicador de impacto que Passos e Costanzi utilizaram foi o nível de emprego nos seis meses anteriores ao recebimento do empréstimo do Proger com o do período seguinte. Barros e Carvalho atentam que a totalidade do emprego gerado não pode ser creditada ao Programa, na medida em que as empresas já estavam criando empregos no período anterior ao recebimento do crédito. Observam, ainda, que mesmo as micros e pequenas empresas (Mpes) que não tomaram empréstimo no período também apresentaram crescimento de emprego, apesar de inferior às tomadoras de empréstimo. Esse é um exemplo de diferenças que podem ocorrer na magnitude do impacto de um programa de microcrédito em virtude do grupo de controle selecionado.

Outro exemplo é o estudo de Coleman apresentado em 1999. O autor realizou um experimento para verificar a importância do grupo de controle nos resultados obtidos. Analisando programas de microcrédito para empreendimentos rurais da Tailândia, Coleman defende que a estimação usualmente empregada para as avaliaçóes de impacto são incorretas quanto ao impacto positivo do crédito sobre os indicadores. Para evitar o viés de seleção, o autor compôs um grupo de controle com os próprios tomadores do empréstimo há um ano do recebimento do crédito. $\mathrm{O}$ estudo verifica que não há impacto sobre ativos, poupanças, vendas ou gastos em educação dos empreendimentos e das famílias pesquisadas, respectivamente, enquanto para os gastos com saúde os efeitos são negativos. Apesar dos resultados, o autor adverte que o caso tailandês é peculiar, devido ao programa avaliado 
emprestar valor médio superior aos outros programas da região.7 Destarte, o estudo de Coleman é seminal por apresentar fortes evidências para se atentar ao viés de seleção.

Nesse sentido, diversos estudos buscam debelar tal viés, como aqueles da Assessing the impact of microenterprise services da United States Agency for International Development (Aims/Usaid) que recomendam comparar antigos clientes com novos clientes, mas que ainda não receberam crédito ou receberam-no há pouco tempo, de modo a eliminar características não mensuráveis, como o espírito empreendedor. Karlan contesta a validade dessa comparação, pois as instituiçóes de crédito originalmente poderiam ter iniciado o serviço com um tipo diferente de cliente, por exemplo, de melhor qualidade ou menor risco, limitando as conclusóes dessas análises (KARLAN, 2001).

Frente a essas críticas, os estudos recentes da Aims se valem de dados longitudinais e de grupos de controle formados por amostra de não-clientes elegíveis, isto é, apresentam características similares ao grupo de tratamento, sendo a tomada de crédito a única diferença entre eles. 8

Quanto aos resultados das avaliaçóes, esse tipo de análise abarca uma ampla diversidade de indicadores que podem ser agrupados em virtude da escolha da unidade avaliada - família ou pequeno e microempreendimento. Assim, as principais contribuiçóes dos estudos de avaliação de impacto se referem à qualidade de vida das famílias pobres. Diversos estudos mostram o impacto positivo do microcrédito sobre a renda familiar, nível de poupança, gastos de consumo, ativos familiares, elevação da freqüência escolar das crianças e a redução da taxa de desemprego, especialmente entre as mulheres. Contudo, a contribuição fundamental proporcionada por esses trabalhos é apresentar evidências estatisticamente significantes de que os programas de microcrédito alcançam seu principal objetivo, isto é, a redução do nível de pobreza das famílias tomadoras de empréstimo. E, nesse caso, segundo Todd, verifica-se forte correlação entre o valor do empréstimo oferecido e o impacto na redução da pobreza (TODD, 2000).

\footnotetext{
${ }^{7}$ Destacamos que estudos realizados por Sebstad (1993) e Walsh (1991) sobre o Kenya, que se utilizando de procedimentos similares, chegam a conclusões opostas.

${ }^{8}$ Churchill (1995) também alerta que não se pode desconsiderar, na formação do grupo de controle, os clientes desistentes, visto que a sua ausência pode levar à sobre estimação dos resultados.
} 
Com relação aos estudos que avaliam a influência do microcrédito sobre os pequenos empreendimentos, em geral, observa-se o impacto positivo do crédito sobre o faturamento, vendas, lucro bruto, margem de lucro, expansão e ingresso do negócio na formalidade. Outro aspecto observado é que o impacto sobre os indicadores, em especial o faturamento e lucro do empreendimento, é maior para os clientes mais antigos e/ou que tomaram empréstimo mais de uma vez, evidências que reforçam o papel dos programas de microfinanças ao longo do tempo.9

Por outro lado, os efeitos na produção são distintos e subordinados ao setor de atividade econômica, ou seja, verifica-se o impacto positivo ou negativo do crédito sobre a produção, dependendo do ramo de atividade em que se encontra o empreendimento. Segundo estudo de Nelson e Bolnick, o microcrédito para pequenos empreendimentos na Indonésia apresentou impacto negativo ou não significativo para 8 dos 29 ramos analisados; enquanto para os demais, apesar de positivo, observa-se um impacto de baixa magnitude para diversos ramos (NELSON, BOLNICK, 1986). Tais resultados fornecem indícios da relevância que deve ser atribuída à focalização quando do desenho dos programas de microcrédito, atentandose às especificidades dos potenciais devedores.

Por sua vez, assim como no nível de produção do empreendimento, os indicadores verificados sobre o nível de emprego são distintos. Freqüentemente não se observa o impacto direto do microcrédito sobre a geração de emprego, e quando ocorre, ele se mostra positivo mas pouco significativo - além de ser distinto entre os setores de atividade econômica.10 Novamente destacamos o estudo sobre o microcrédito na Indonésia de Nelson e Bolnick, no qual se verifica o impacto positivo sobre geração de postos de trabalho nos setores agrícolas e industriais, enquanto no setor de Construção o impacto é negativo (NELSON, BOLNICK, 1986).

Todavia, apesar de, em geral, se observar uma reduzida taxa de crescimento dos postos de trabalho entre os tomadores de empréstimo, tal taxa ainda se revela superior em relação aos empreendimentos do grupo de controle. A despeito das reduzidas evidências acerca da geração de emprego, observa-se

\footnotetext{
${ }^{9}$ Como verificados por Creevey et al. (1995) na Guiné; e por Montgomery (1996) em Bangladesh.

10 Contudo, nesse caso, alguns estudos observam correlações positivas com outras variáveis, como o crescimento dos lucros, por exemplo (COPESTAKE, BHALOTRA, JOHNSON, 2001).
} 
o efeito positivo do crédito na manutenção dos postos de trabalho e sobre os salários dos trabalhadores, além do aumento do número de horas e dias ocupados.

Outra contribuição relevante encontrada por Nelson e Bolnick, por exemplo, é que, em alguns setores, a redução do subemprego é maior que a geração de emprego, representando melhores condições trabalhistas para esse tipo de empregado, de baixa renda e com menor qualificação. Esses estudos verificam ainda os fatores que influenciam o menor efeito marginal do crédito, como a ausência de assistência técnica, baixo valor do empréstimo - insuficiente para elevar a produção a um nível eficiente - e o fato do crédito normalmente ser oferecido para empreendimentos que já possuem um nível eficiente de produção.

Os programas latino-americanos, assim como a maioria dos seus congêneres de outras regiôes do globo, apresentam avaliaçốes positivas. Estudo quase experimental, realizado por Mosley, em 1996, para a Bolívia, país precursor das açóes de microcréditos na América do Sul, apontou que $91 \%$ dos tomadores de empréstimo apresentaram aumento na renda, especialmente, os mais pobres. A renda elevou-se mais para os devedores do que para grupo de controle, além disso, entre os que receberam crédito, 39\% aumentaram a contratação de empregados, sobretudo os empreendimentos mais ricos, e 26\% aplicaram o empréstimo em novas tecnologias (MOSLEY, 1996b).

A Organización de Desarrollo Empresarial Femenino (ODEF) de Honduras foi avaliada, em 1998, contrastando 76 tomadores de empréstimos com 70 tomadores de empréstimo elegíveis, mas que não tinham solicitado crédito e 23 que tinham tomado crédito anteriormente (EDGECOMB, GARBER, 1998). Os resultados indicaram que os tomadores de empréstimos apresentaram lucros $75 \%$ maiores que os componentes dos grupos de controle, além de maiores aumentos na poupança, renda e investimento em ativos.

O programa peruano Mibanco foi avaliado em pesquisa quase experimental contrastando tomadores de empréstimos com não clientes de características similares em 1997 - 701 domicílios - e em 1999 - 529 domicílios: 305 do grupo de tratamento, 175 do grupo de controle, 38 de novos entrantes 
e 11 que participaram de estudo de caso. O impacto positivo do crédito entre os empreendimentos micros se mostrou elevado e significante nos dois períodos. Entre as variáveis analisadas, com relação aos componentes do grupo de controle, a renda dos novos ingressantes no programa foi superior, assim como, a renda per capta dos tomadores de empréstimo. A participação no programa criou nove dias adicionais de emprego por mês, inclusive 3,26 dias para trabalhadores não domiciliares. Os autores estimam que 17.414 postos de trabalho foram gerados pela ação do crédito (DUNN, ARBUCKIE, 2001).

\section{Análise de desempenho (Tipo II)}

O procedimento mais simples de se verificar os efeitos de um programa de microcrédito é através de análises de desempenho que comparam a performance pós-crédito de uma série de indicadores dos tomadores de empréstimo. Diversos trabalhos seguem esse procedimento tanto pela indisponibilidade de dados necessários para uma análise mais profunda, como pelo elevado custo e dificuldade de se realizar uma pesquisa ao longo do tempo e/ou com um grupo de controle adequado. Destarte suas limitaçóes, as análises de desempenho, em um primeiro momento, apresentam indícios sintéticos e pontuais dos efeitos verificados entre os tomadores de empréstimo do programa, ainda que não se possa afirmar que tais variações são contribuiçóes diretas da oferta de crédito.

Freqüentemente, os estudos desse tipo apresentam resultados positivos sobre os indicadores analisados. Análises que tomam como referência a unidade domiciliar mostram redução do grau de pobreza assim como a elevação da renda média familiar. Efeitos positivos também ocorrem para as avaliaçóes do microcrédito em unidades produtivas - micro e pequenos negócios. Nesses estudos verifica-se a elevação de vendas, o lucro bruto, a margem de lucro, os ativos, o valor adicionado do produto, a geração de emprego assalariado direto e indireto, distinto entre setores da economia, o número de horas trabalhadas, e o salário real.

Outro aspecto observado refere-se à ocorrência de mudanças técnicas na produção, especialmente em atividades agrícolas (SUTORO, 1990); a maior rentabilidade do empreendimento beneficiado perante capitais de terceiros 
(GRABNER, 2003); e a verificação de distribuição significativa de recursos para um elevado número de beneficiários (CARDOSO, FAÇANHA, MARINHO, 2002).

Apesar de escassas, também existem evidências de efeitos negativos de programas de microcrédito, como o caso da Alexandria Businessmen's Association (ABA) no Egito, que apresentou uma redução do emprego de 3,0 para de 2,8 em micro e pequenos estabelecimentos que tomaram empréstimos. Por outro lado, neste mesmo caso, verificam-se outros efeitos que são positivos, como por exemplo, $70 \%$ dos tomadores aumentaram o número de vendas e $67 \%$ obtiveram elevação no faturamento (OLDHAM, 1994).

No Caribe, o programa Microenterprise Development Project da Jamaica contou, em 1993, com uma avaliação de desempenho em 25 empresas receptoras de crédito (GUPTA, 1993). O estudo mostrou um crescimento de $7 \%$ das vendas e de $4 \%$ nos salários, além de 1.156 empregos criados.

O governo chileno, por outro lado, institui, em 1992, um programa que objetivava não apenas incluir micro e pequenos empresários no mercado de crédito como também incentivar bancos e outras organizações, por exemplo, Imfs e sindicatos, a criar linhas de atendimento para esse perfil de clientes. Nesse sentido, o governo estabeleceu um sistema de subsídios a serem pagos para cada empréstimo concedido - Programa de aceso ao credito: teto para o montante de empréstimo a cada micro ou pequena empresa e subsídio decrescente a cada tomada de empréstimo.

Segundo avaliação realizada, o programa introduziu uma mudança estrutural no sistema de crédito, na medida em que os grandes bancos que atuam no Chile consideraram esse segmento como um mercado específico e criaram ferramentas adequadas para absorvê-lo, por exemplo, analisando inicialmente o desempenho do pequeno negócio a partir do desempenho médio do mercado de micro e pequenas empresas.

Merino destaca três causas que tornaram o programa chileno bem sucedido. Inicialmente, o programa permitiu que os bancos assumissem riscos que não assumiriam devido ao baixo retorno obtido a partir dos empréstimos a esse segmento. Em segundo lugar o subsídio permitiu que o crédito formal fosse efetivado com custos menores de transação. E em 
terceiro lugar, intermediários e fornecedores de crédito que cobravam taxas acima daquelas definidas pelo Banco Central do Chile saíram do mercado. Esse autor destaca, ainda, os seguintes indicadores: 35\% das microempresas chilenas são tomadoras de empréstimos; 97\% e 98\% dos tomadores de empréstimos dos Bancos Estado e Banefe, respectivamente, tornaram-se clientes regulares; $80 \%$ dos empréstimos foram aplicados diretamente no negócio (MERINO, 2007).

Por fim, destacamos o caso do FONDESO (Fondo para el Desarrollo Social) na Cidade do México, um fundo descentralizado de financiamento público, criado em 2002, diante de um quadro de crescente exclusão da população local que enfrentava elevados índices de pobreza e desemprego. Dentre as diversas políticas públicas de microcrédito existentes no México, o FONDESO destaca-se por oferecer um conjunto adicional de serviços não financeiros - como cursos de capacitação e assistência na comercialização de serviços e produtos - além de suas três linhas de auxílio financeiro - Programa de Microcrédito para o auto-emprego; Programa de Financiamento a Micro e Pequena Empresa; e Programa de Fundo de Garantia. Ou seja, o Fundo náo apresenta um caráter apenas assistencialista, mas visa combater às carências sociais e econômicas através de um desenvolvimento local sustentável.

O FONDESO se caracteriza principalmente por sua linha de crédito voltado para o auto-emprego. Assim, segundo informaçóes dos gestores, o Fundo gerou mais de 44 mil empregos diretos em 2002, e 25 mil em 2003, beneficiando uma população superior a 160 mil pessoas em cada ano. Ademais, a percepção dos beneficiários em relação ao Programa é bastante favorável, sendo que cerca de $90 \%$ afirmam que houve melhorias na satisfação de suas necessidades básicas, como saúde, alimentação, educação, etc. De menor magnitude, tanto em termos de número de operaçóes, como de valores movimentados, a linha de crédito voltado para as pequenas e microempresas e o Programa de Fundo de Garantia igualmente apresentam resultados positivos, oferecendo melhores condiçóes para que os empreendimentos carentes possam levar adiante e até expandir suas atividades econômicas. 


\section{Considerações finais}

Os estudos resenhados deixam claro que os programas de microcrédito atingem e tem impacto positivo sobre a vida material dos mais pobres, permite-lhes enfrentar melhor os riscos, tirar vantagem das suas oportunidades de emprego e renda, reduzindo-lhe, assim, a sua vulnerabilidade diante das incertezas promovidas pelos mercados. A maior parte dos estudos analisados revela impacto positivo sobre a renda das famílias, e impacto positivo sobre o faturamento e o nível de emprego das micro e pequenas empresas.

Devemos destacar ainda que a oferta de microcrédito se constituiu em um programa social inovador, pelo menos, por duas características. A primeira refere-se ao fato dos programas buscarem, e diversos já atingiram, a própria sustentabilidade financeira, ou seja, buscam a auto-suficiência financeira. A segunda marca é que, diferentemente da maioria dos programas de combate à pobreza, este opera sob princípios estritamente de mercado. Ou seja, os objetivos de quaisquer dos programas de microfinanças instituídos visa dois objetivos: oferecer serviços - públicos, para-públicos e privados - à população pobre e tornar-se auto-sustentável, obedecendo estritamente às regras de mercado. Segundo os dados do sistema Mix-Market, publicados em 2006, todas as Imfs melhoram o seu desempenho financeiro, depois de 2001, e dois terços do total tinham alcançado a auto-suficiência. A literatura especializada sugere um período de 7 a 10 anos para atingir que possam atingir a sustentabilidade e a necessidade de ter escala para alcançar sucesso.

A prioridade entre obter a independência financeira ou aumentar o número de pobres atendidos difere entre as diversas Imfs, alterando a assertiva anterior sobre o período para a auto-suficiência. Christen aponta que as Imfs que atendem os mais pobres e emprestam pequenos montantes e que, em geral, são financiadas por meio de doações, atingem a fronteira da eficiência e não têm condiçóes de tornarem-se auto-suficientes a não ser que mudem o foco da clientela.

A análise desse tipo de Imf por região, segundo o autor, mostra que esse tipo tende a fixar as suas taxa de juros em níveis relativamente altos, apresenta os maiores indicadores de produtividade dos funcionários frente aos demais, adota técnicas de liberação de empréstimos de menor custo e comprime os salários de seus funcionários (CHRISTEN, 2000). Dessa maneira, o objetivo 
dos doadores é que determinará se a Imf continuará a atender o segmento mais pobre ou se alterará o seu foco de atendimento, optando por clientes de maior nível de renda.

Embora os resultados dos programas de microcrédito sejam promissores, e, em alguns países, esses programas se juntem às políticas públicas de maior sucesso, as ações de microfinanças exigem ampliação, diversidade e aperfeiçoamento, sobretudo nos países da América do Sul, para fazerem jus à atribuição de se constituírem em um programa de inclusão social. Assim, aumentar a capilaridade dos serviços, criar profundidade e diversidade na oferta de produtos, formar mercados nacionais para microfinanças, utilizar tecnologias que rebaixem os custos operacionais e ampliar o número de ofertantes para alcançar maior competitividade, se encontram entre as prioridade a serem seguidas para estender os serviços financeiros à população mais pobre.

A construção de um sistema financeiro inclusivo requer a oferta de uma gama de produtos que vai além dos serviços de microcrédito, por exemplo: poupança de curto, médio e longo prazo, microcréditos flexíveis, seguros de vida e saúde, finanças imobiliária, investimento financeiro, fluxos de remessa de dinheiro para poupança e habitação, finanças de consumo e transferência de pagamentos, nacional e internacional. 


\section{Referências Bibliográficas}

ARAÚJO, Tarcisio Patrício de; LIMA, Roberto Alves de. Políticas públicas de emprego como instrumentos de redução da pobreza e da desigualdade no Brasil. In: CIMADAMORE, Alberto et al (Orgs.). A pobreza do Estado: reconsiderando o papel do Estado na luta contra a pobreza global. Buenos Aires: CLACSO, 2006.

BARNES, Carolyn. Microfinance program clients and impact: an assessment of Zambuko Trust, Zimbabwe. Washington D.C.: AIMS, 2001.

BARROS, Ricardo Paes de; CARVALHO, Mirela de. Políticas ativas de emprego e renda. Brasília: Nota Técnica, IPEA, 2002.

BUCKLEY, Graeme. Financing the Jua Kali sector in Kenya: the KREP Juhudi scheme and Kenya Industrial Estates Informal Sector Programme. In: HULME, David; MOSLEY, Paul (Orgs.). Finance against poverty. Volume II: Country case studies. London: Routledge, 1996a.

. Rural and agricultural credit in Malawi: a study of the Malawi Mudzi Fund and the smallholder agricultural administration. In: HULME, David; MOSLEY, Paul (Orgs.). Finance against poverty. Volume II: Country case studies. London: Routledge, 1996b.

CARDOSO, Larry C.; FAÇANHA, Luís O.; MARINHO, Alexandre. Avaliação de programas sociais (PNAE, PLANFOR, PROGER): eficiência relativa e esquemas de incentivo. Texto para Discussáo, Rio de Janeiro, IPEA, n. 859, 2002.

CGAP. Advancing Financial Access for the World's Poor. Disponível em: http:// www.cgap.org/p/site/c/template.rc/1.11.1792/1.26.2116. Acesso em: 06/2007.

CHARNES, A. et al. Measuring the efficiency of decision making units. European Journal of Operational Research, v. 2, p. 429-444, 1978.

CHEN, Martha A.; SNODGRASS, Donald. Managing resources activities, and risk in urban India: the impacts of SEWA Bank. Washington D.C.: AIMS, 2001. 
CHRISTEN, Robert Peck. Bulletin highlights. MicroBanking Bulletin, Washington DC, n. 4, Feb. 2000.

. Microentreprises, microcredit: access to finance, In: 1st International microfinance regulation and supervision meeting. Salvador: BCB/BID/ SEBRAE, 2005.

CHURCHILL, Craig F. The impact of credit on informal sector enterprises in South Africa: a study of Get Ahead Foundation's Stokvel Lending Programme. Clark University MA. Tese, Worchester, MA, 1995. Apud SEBSTAD, Jennefer; CHEN, Gregory. Overview of studies on the impact of microenterprise credit. AIMS Project Working Paper. Washington, D.C.: USAID Office of Microenterprise Development, 1996.

COLEMAN, Brett. The impact of group lending in Northeast Thailand. Journal of Development Economics, v. 60, p. 105-142, 1999.

CONSULTIVE GROUP TO ASSIST THE POOR; WORLD BANK. Scaling up poverty reduction: case studies in microfinance. Washington DC.: 2004.

COPESTAKE, James; BHALOTRA, Sonia; JOHNSON, Susan. Assessing the impact of microcredit: a Zambian case study. Journal of Development Studies, v. 37, n. 4, p. 81-100, 2001.

CREEVEY, Lucy E. et al. Evaluation of the impacts of PRIDE/VITA (The guinea rural enterprise development project). GEMINI Technical Report, Bethesda, MD, n. 94, 1995. Apud SEBSTAD, Jennefer; CHEN, Gregory. Overview of studies on the impact of microenterprise credit. AIMS Project Working Paper. Washington, D.C.: USAID Office of Microenterprise Development, 1996.

DUNN, Elizabeth; ARBUCKIE, J. Gordan, Jr. The impacts of microcredit: a case study from Peru. Washington D.C.: AIMS, 2001.

EDGECOMB, Elaine; GARBER, Carter. Practitioner-led impact assessment: a test in Honduras. Washington D.C: AIMS, 1998.

ENTERPRISING SOLUTIONS GLOBAL CONSULTING, LLC. UNCDF Microfinance programmed impact assessment: Nigeria companion report. UNCDF, Dec. 2003. 
GARRIDO, Celso. Fondo para el desarrollo social de la Ciudad de México. In: FOSCHIATTO, Paola; STUMPO, Giovanni (Orgs.). Políticas municipales de microcrédito. Un instrumento para la dinamización de los sistemas productivos locales. Estúdios de caso en América Latina. CEPAL, 2006.

GRÄBNER, Selia. Avaliação do desempenho das empresas financiadas pelo PROGER - na regiāo de Santa Maria, RS. São Paulo, 2003. Dissertação (Mestrado) - Faculdade de Economia, Administração e Contabilidade da Universidade de São Paulo - FEA/USP, 2003.

GOLDBERG, Nathanael. Measuring the impact of microfinance: taking stock of what we know. Washington DC: Grameen Foundation, 2005.

GUPTA, Surendra; DAVALOR, Mario D. Midterm evaluation of the microenterprise development project of Jamaica. GEMINI Technical Report, Bethesda, MD, n. 59, 1993. Apud SEBSTAD, Jennefer; CHEN, Gregory. Overview of studies on the impact of microenterprise credit. AIMS Project Working Paper. Washington, D.C.: USAID Office of Microenterprise Development, 1996.

HARTARSKA, Valentina. An impact analysis of microfinance in Bosnia and Herzegovina. Mimeo. 2007.

HOSSAIN, Mahabub. Credit for the alleviation of rural poverty: the Grameen Bank in Bangladesh. Research Report, Washington D.C., IFPRI, n. 65, 1988.

HULME, David. Impact assessment methodologies for microfinance: theory, experience and better practice. World Development, v. 28, n. 1, p. 79-98, 2000.

HULME, David; MONTGOMERY, Richard; BHATTACHARYA, Debapriya. Mutual finance and the poor: a study of the federation of thrift and credit cooperatives in Sri Lanka (SANASA). In: HULME, David; MOSLEY, Paul (Orgs.). Finance against poverty. Volume II: Country case studies. London: Routledge, 1996. 
IBASE. Democracia viva: avaliação PROGER Urbano, PROGER Rural e PRONAF. Rio de Janeiro: Segmento, 1999.

KARLAN, Dean. Microfinance impact assessments: the perils of using new members as a control group. Journal of microfinance, v. 3, n. 2, p. 76-85, 2001.

KHANDKER, Shahidur. Micro-finance and poverty: evidence using panel data from Bangladesh. World Bank Economic Review, v. 19, n. 2, p. 263-286, 2005.

MERINO, Vito Sciaraffia. Auctioning subsidies: Chile's Access to Credit Program. In: BALKENHOLD, Bernd. Microfinance and public policy. New York: Palgrave Mcmillan \& ILO, 2007.

MIX-MARKET ORGANIZATION. Disponível em: http://www. mixmarket.org. Acesso em: 06/2007.

MKNELLY, Barbara; WATETIP, Chatree. Impact evaluation of Freedom from Hunger's Credit with Education Program in Thailand. Freedom From Hunger Foundation. Davis CA: 1993.

MKNELLY, Barbara et al. Practitioner-led impact assessment: a test in Mali. International Journal of Economic Development, v. 1, n. 2, p. 120-164, 1999.

MONTGOMERY, Richard et al. Credit for the poor in Bangladesh: the BRAC rural development programme and the government Thana Resource Development and Employment Programme. In: HULME, David; MOSLEY, Paul (Orgs.). Finance against poverty. Volume II: Country case studies. London: Routledge, 1996.

MONZONI, Mario Prestes, Neto. Impacto em renda do microcrédito: uma investigação empírica sobre geração de renda do Crédito Popular Solidário (São Paulo Confia), no Município de São Paulo. São Paulo, 2006. Tese (Doutorado) - Escola de Administração de Empresas, Fundação Getúlio Vargas, 2006. 
MOSLEY, Paul. India: regional rural banks. In: HULME, David; MOSLEY, Paul (Orgs.). Finance against poverty. Volume II: Country case studies. London: Routledge, 1996.

. Indonesia: BKK, KURK and the BRI unit desa institutions. In: HULME, David; MOSLEY, Paul (Orgs.). Finance against poverty. Volume II: Country case studies. London: Routledge, 1996.

. Metamorphosis from NGO to commercial bank: the case of Bancosol in Bolivia. In: HULME, David; MOSLEY, Paul (Orgs.). Finance against poverty. Volume II: Country case studies. London: Routledge, 1996.

NEIL, Catherine et al. The Kenya rural enterprise programme under cooperative agreement No. AID-615-0238-A-00-7026-00: a final evaluation. GEMINI Technical Report, Bethesda, MD, n. 77, 1994. Apud SEBSTAD, Jennefer; CHEN, Gregory. Overview of studies on the impact of microenterprise credit. AIMS Project Working Paper. Washington, D.C.: USAID Office of Microenterprise Development, 1996.

NELSON, Eric; BOLNICK, Bruce R. Survey methods for assessing small credit programs evaluating impact KIK/KMKP credits. Jakarta: 1986.

OLDHAM, Linda et al. Measuring socioeconomic impact of credit on SMI: assessment of the monitoring system used by the Alexandria Businessmen's Association, Egypt. GEMINI Technical Report, Bethesda, MD, n. 76, 1994. Apud SEBSTAD, Jennefer; CHEN, Gregory. Overview of studies on the impact of microenterprise credit. AIMS Project Working Paper. Washington, D.C.: USAID Office of Microenterprise Development, 1996.

PASSOS, Alessandro F. dos. Avaliação de políticas de financiamento a micro e pequenas empresas na geração de postos de trabalho. O caso do Programa de Geração de Emprego e Renda (PROGER). Rio de Janeiro, 2005. Dissertação (Mestrado) - Faculdade de Economia, Universidade Federal Fluminense UFF, 2005.

PASSOS, Alessandro F. dos; COSTANZI, Rogério Nagamine. Evolução e perspectiva dos programas de geração de emprego e renda. Nota técnica, IPEA, 2002a. 
- Proger urbano: uma avaliação da geração de empregos formais. Boletim Mercado de Trabalho - Conjuntura e Análise, IPEA, v. 18, $2002 \mathrm{~b}$.

PITT, Mark; KHANDKER, Shahidur. The impact of group-based credit programs on poor households in Bangladesh: does the gender of participants matter? Journal of Political Economy, v. 106, n. 5, p. 958-996, 1998.

SEBSTAD, Jennefer. Get ahead foundation credit programs in South Africa: the effects of loans on client enterprises, GEMINI Technical Report, Bethesda, MD, n. 44, 1992. Apud SEBSTAD, Jennefer; CHEN, Gregory. Overview of studies on the impact of microenterprise credit. AIMS Project Working Paper. Washington, D.C.: USAID Office of Microenterprise Development, 1996.

SEBSTAD, Jennefer; LOZA, Sara. "Lending and learning: formal banks and microenterprise in Egypt". Relatório para Ford Foundation Cairo. Community Economics Corporation. Washington, D.C, 1993. Apud SEBSTAD, Jennefer \& CHEN, Gregory. "Overview of studies on the impact of microenterprise credit”. AIMS Project Working Paper. Washington, D.C.: USAID Office of Microenterprise Development, 1996.

SEBSTAD, Jennefer; WALSH, Martin. Microenterprise credit and its effects in Kenya: an exploratory study. Relatório preparado para USAID AFR/MDI e S\&T/WID. Washington D.C.: Coopers and Lybrand, 1991.

SUTORO, Ann Dunham. KUPEDES Development impact survey: briefing booklet. BRI, Planning, Research and Development Department, 1990.

TODD, Helen. Poverty reduced through microfinance: the impact of ASHI in the Philippines. Washington D.C.: AIMS, 2000.

VENGROFF, Richard; CREEVEY, Lucy. Evaluation of project impact: ACEP component of the community enterprise development project. Relatório para USAID/Dakar. Storrs: University of Connecticut, 1994. 
Anexo - Relação dos programas de microfinanças avaliados, segundo país de origem a) Avaliação de impacto (Tipo I)

\begin{tabular}{|c|c|c|}
\hline País & Programa de microfinança & Autor(es)/(ano) \\
\hline África do Sul & Get Ahead Foundation & CHURCHILL (1995) \\
\hline Bangladesh & Grameen Bank & HOSSAIN (1988) \\
\hline Bangladesh & $\begin{array}{l}\text { BRAC } \\
\text { Thana Resource Development and } \\
\text { Employment Program (TRDEP) }\end{array}$ & MONTGOMERY (1996) \\
\hline Bangladesh & $\begin{array}{l}\text { Grameen Bank; BRAC } \\
\text { (Bangladesh Rural Advancement } \\
\text { Commitee); RD-12 (Rural } \\
\text { Development) }\end{array}$ & $\begin{array}{l}\text { PITT \& KHANDKER (1998); } \\
\text { KHANDKER (2005) }\end{array}$ \\
\hline Bolívia & BancoSol & MOSLEY (1996) \\
\hline $\begin{array}{l}\text { Bósnia- } \\
\text { Herzegovina }\end{array}$ & $\begin{array}{l}\text { Todas as instituiçóes que operam } \\
\text { no mercado de crédito }\end{array}$ & HARTARSKA (2007) \\
\hline Brasil & PROGER Urbano & $\begin{array}{l}\text { PASSOS \& COSTANZI (2002a); } \\
\text { PASSOS \& COSTANZI (2002b); } \\
\text { PASSOS (2005) }\end{array}$ \\
\hline Filipinas & ASHI & TODD (2000) \\
\hline Guiné & $\begin{array}{l}\text { Guinea Rural Enterprise } \\
\text { Development Project (PRIDE/ } \\
\text { VITA) }\end{array}$ & CREEVEY et al (1995) \\
\hline Honduras & $\begin{array}{l}\text { Organización de Desarrollo } \\
\text { Empresarial Femenino (ODEF) }\end{array}$ & $\begin{array}{l}\text { EDGECOMB \& GARBER } \\
(1998)\end{array}$ \\
\hline Índia & $\begin{array}{l}\text { Dois bancos rurais regionais } \\
\text { (Manjira e Sangameshawara) }\end{array}$ & MOSLEY (1996) \\
\hline Índia & SEWA & CHEN \& SNODGRASS (2001) \\
\hline Indonésia & KIK/KMKP & NELSON \& BOLNICK (1986) \\
\hline Indonésia & BKK; KURK; BRI & MOSLEY (1996) \\
\hline Jamaica & $\begin{array}{l}\text { Microenterprise Development } \\
\text { Project }\end{array}$ & GUPTA \& DAVALOR (1993) \\
\hline Malawi & Malawi Mudzi Fund & BUCKLEY (1996) \\
\hline Mali & Credit with Education & MKNELLY et al (1999) \\
\hline Nigéria & $\begin{array}{l}\text { LAPO (Lift Above Poverty } \\
\text { Organisation) }\end{array}$ & $\begin{array}{l}\text { ENTERPRISING SOLUTIONS } \\
\text { GLOBAL CONSULTING }(2003)\end{array}$ \\
\hline Peru & Mibanco & DUNN \& ARBUCKLE (2001) \\
\hline
\end{tabular}


Anexo - Relação dos programas de microfinanças avaliados, segundo país de origem a) Avaliação de impacto (Tipo I)

\begin{tabular}{|c|c|c|}
\hline País & Programa de microfinança & Autor(es)/(ano) \\
\hline Quênia & $\begin{array}{l}\text { Keny Rural Enterprise Programme } \\
\text { (K-REP); Informal Sector } \\
\text { Programme (ISP) }\end{array}$ & BUCKLEY (1996) \\
\hline Senegal & $\begin{array}{l}\text { Agence de Credt pour l'Enterprise } \\
\text { Privee (ACEP) }\end{array}$ & $\begin{array}{l}\text { VENGROFF \& CREEVEY } \\
(1994)\end{array}$ \\
\hline Tailândia & $\begin{array}{l}\text { Freedom from Hunger Credit with } \\
\text { Education Program }\end{array}$ & MKNELLY \& WATETIP (1993) \\
\hline Tailândia & $\begin{array}{l}\text { Rural Friends Association; } \\
\text { Foundation for Integrated } \\
\text { Agricultural Management }\end{array}$ & COLEMAN (1999) \\
\hline Zâmbia & $\begin{array}{l}\text { Peri-Urban Lusaka Enterprise } \\
\text { Project (PULSE) }\end{array}$ & $\begin{array}{l}\text { COPESTAKE, BHALOTRA, } \\
\text { JOHNSON (2001) }\end{array}$ \\
\hline Zimbabue & Zambuko Trust & BARNES (2001) \\
\hline
\end{tabular}


b) Análise de desempenho (Tipo II)

\begin{tabular}{|c|c|c|}
\hline País & Programa de microfinança & Autor(es)/(ano) \\
\hline África do Sul & Get Ahead Foundation & SEBSTAD (1992) \\
\hline Brasil & $\begin{array}{l}\text { PROGER Urbano; PROGER } \\
\text { Rural; PRONAF }\end{array}$ & IBASE (1999) \\
\hline Brasil & $\begin{array}{l}\text { Programa Nacional de } \\
\text { Alimentação (Pnae); Plano } \\
\text { Nacional de Qualificação } \\
\text { (Planfor); e PROGER }\end{array}$ & $\begin{array}{l}\text { CARDOSO, FAÇANHA, } \\
\text { MARINHO (2002) }\end{array}$ \\
\hline Brasil & PROGER Urbano & GRÄBNER (2003) \\
\hline Brasil & $\begin{array}{l}\text { Crédito Popular Solidário (São } \\
\text { Paulo Confia) }\end{array}$ & MONZONI (2006) \\
\hline Chile & Bancos Estado e Banefe & MERINO (2007) \\
\hline Egito & $\begin{array}{l}\text { National Bank for Development } \\
\text { (NBD); Principal Bank for } \\
\text { Development and Agricultural } \\
\text { (PBDAC) }\end{array}$ & SEBSTAD \& LOZA (1993) \\
\hline Egito & $\begin{array}{l}\text { Alexandria Businessmen's } \\
\text { Association (ABA) }\end{array}$ & OLDHAM et al (1994) \\
\hline Indonésia & BRI & SUTORO (1990) \\
\hline México & $\begin{array}{l}\text { FONDESO (Fondo para el } \\
\text { Desarrollo Social) }\end{array}$ & GARRIDO (2006) \\
\hline Quênia & K-REP & $\begin{array}{l}\text { SEBSTAD \& WALSH (1991); } \\
\text { NEIL et al (1994) }\end{array}$ \\
\hline Sri Lanka & $\begin{array}{l}\text { Federation of Thrift and Credit } \\
\text { Cooperatives in Sri Lanka } \\
\text { (SANASA) }\end{array}$ & $\begin{array}{l}\text { HULME, MONTGOMERY, } \\
\text { BHATTACHARYA (1996) }\end{array}$ \\
\hline
\end{tabular}

